\title{
Compatibility of Biofuel/Diesel Blends on Storage Tank Material +
}

\author{
H. N. MEENAKSHI, ANISHA ANAND, R. SHYAMALA and R. SARATHA
}

Department of Chemistry, Avinashilingam Institute for Home Science and Higher Education for Women, Coimbatore - 43, Tamilnadu, India

shyamala1951@gmail.com

Received 10 January 2013/ Accepted 15 February 2013

\begin{abstract}
Non- edible oils from the plant seeds are the most promising alternative fuel for diesel engines as they are renewable, environment friendly, non-toxic, biodegradable, no sulphur and aromatics, favourable heating value and higher cetane number. But their inherently high viscosity compared to fossil diesel is undesirable for diesel engines. Lowering the viscosity can be achieved by breaking the triglyceride molecules and separating the fatty acid molecules from the glycerine molecules - transesterification. Biodiesel is more susceptible to oxidative attack than diesel fuel. The rate of oxidation is determined by the degree of unsaturation in the fatty acid alkyl ester chain, water content and environmental factors such as temperature, nature of storage container and air exposure during storage. Acceptable storage tank materials include mild steel, stainless steel, fluorinated polyethylene and polypropylene. Biodiesel has a solvent effect which releases the deposits accumulated on tank walls leading to corrosion. In the present investigation, the compatibility of biodiesel from Pongamia pinnata (PBD) and Jatropha curcus (JBD) and their different blends with commercial diesel $(5 \%, 10 \%$ and $20 \%)$ with mild steel has been studied by mass loss method for a period of $100 \mathrm{~h} .3 \% \mathrm{NaCl}$ was used to depict water contamination. Though negligible corrosion rates were observed in both the biodiesels, corrosion rate in JBD was found to be higher. The surface topography of the metal samples after the exposure period was analyzed by scanning electron microscopy. The surface profile, pit distribution and pit density of the metal coupons were determined by laser profilometry. The wettability studies also supported the non corrosive nature of the biodiesel used.
\end{abstract}

Keywords: Biodiesel, Pongamia pinnata, Jatropha curcus, Corrosion, Wettability

\section{Introduction}

Biomass can be converted directly into liquid fuels, called "biofuels," which is a true panacea for all modern energy challenges and environmental problems. Vegetable oils represent a ready, renewable and clean energy source for diesel engine but they pose some problem when used directly in an engine as a diesel substitute. These problems can be solved, if the neat vegetable oils are chemically modified to biodiesel, which is similar in characteristics to diesel fuel. 
Biodiesel is a liquid hydrocarbon fuel composed of fatty acid monohydric alcohol esters whose molecular composition may change according to the type of feed stocks. Most of the biodiesel currently being produced is mainly dependent on edible oil sources ${ }^{1}$. The successful adoption of biodiesel is reliant on the supply of feedstock from non-food crops $^{2}$ which are easily available in many parts of the world including India and are very economical compared to edible oils.

Biodiesel is more susceptible to oxidative attack than diesel fuel due to the presence of water $^{3}$, environmental factors such as temperature, nature of storage container ${ }^{4}$ and air exposure during storage. For long term storage stability of biodiesel and its blends adequate data are not available. Hence the present paper investigates and compares the corrosivity of Pongamia pinnata (PBD) and Jatropha curcus (JBD) biodiesels and their blends on mild steel (MS) which is an acceptable storage tank material.

\section{Experimental}

Pongamia and Jatropha biodiesels were procured from a dealer at Coimbatore, Tamilnadu and examined for various physicochemical characteristics and the results were presented in Table 1 with ASTM D6751 and ASTM D975 standard.

Table 1. ASTM standards and fuel properties of Pongamia, Jatropha biodiesels

\begin{tabular}{|c|c|c|c|c|c|}
\hline Parameters & $\begin{array}{l}\text { ASTM } \\
\text { D975 }\end{array}$ & $\begin{array}{l}\text { ASTM } \\
\text { D6751 }\end{array}$ & PBD & JBD & Unit \\
\hline Flash point & $52 \min$ & $130.0 \mathrm{~min}$ & 126 & 169 & ${ }^{\circ} \mathrm{C}$ \\
\hline Water content and sediment & $0.050 \max$ & $0.050 \max$ & 0.0322 & 0.05 & $\%$ vol \\
\hline Kinematic viscosity $40^{\circ} \mathrm{C}$ & $1.9-4.1$ & $1.9-6.0$ & 6.06 & 5.4 & $\mathrm{~mm}^{2} / \mathrm{sec}$ \\
\hline Sulfated Ash & $0.01 \max$ & $0.020 \max$ & 0.01 & 0.02 & $\%$ mass \\
\hline $\begin{array}{l}\text { Sulfur (Grade No. } 2 \text { - Low } \\
\text { sulfur/S } 500 \text { grade) }\end{array}$ & $0.05 \max$ & $0.05 \max$ & 0.0013 & 0.0006 & $\%$ mass \\
\hline Copper strip corrosion & No. 3 max & No. 3 max & 2 & 1 & - \\
\hline Cetane & $40 \mathrm{~min}$ & $47 \mathrm{~min}$ & 62.0 & 53 & - \\
\hline Carbon residue & $0.35 \max$ & $0.050 \max$ & 0.02 & 0.058 & $\%$ mass \\
\hline Acid number & - & $0.80 \max$ & 0.3 & 3.2 & $\mathrm{Mg} \mathrm{KOH} / \mathrm{g}$ \\
\hline Free glycerin & - & $0.020 \max$ & 0.01 & 0.02 & $\%$ mass \\
\hline Total glycerin & - & $0.240 \max$ & 0.12 & 0.25 & $\%$ mass \\
\hline Phosphorous contents & - & $0.001 \max$ & 0.0001 & 0.0001 & $\%$ mass \\
\hline Distillation temperature & $282-338$ & $360 \max$ & 242 & 330 & ${ }^{\circ} \mathrm{C}$ \\
\hline Aromaticity & $35 \max$ & - & - & - & $\%$ vol. \\
\hline
\end{tabular}

Commercially available MS sheets $(99.6 \% \mathrm{Fe}, 0.011 \% \mathrm{Si}, 0.008 \% \mathrm{Ni}, 0.222 \% \mathrm{Mn}$, $0.03 \% \mathrm{P}, 0.026 \% \mathrm{~S}, 0.003 \% \mathrm{Cr}, 0.102 \% \mathrm{C}$ and $0.035 \% \mathrm{Mo}$ ) were machined into coupons of an area of $33.9 \mathrm{~cm}^{2}$ (ASTM G184) used for the study. The various test media used for the study are $100 \%$ biodiesel (B100), biodiesel with $1 \%$ of $3 \% \mathrm{NaCl}$ (B99) and $3 \% \mathrm{NaCl}$, commercial diesel (CD) and its blends (B5, B10 and B20).

\section{Mass loss measurements}

The metal coupons were immersed in triplicate in various test media for a period of $100 \mathrm{~h}$. After the immersion period, the cleaning of the samples was carried out and the corrosion rates were calculated as per ASTM G1. The conductivity was measured using a conductivity meter (Equiptronics EQ-660A) before and after exposure of coupons. 


\section{Surface morphology}

The change in surface morphology of the samples after the exposure to PBD and JBD was characterized by scanning electron microscopy (SEM) and laser profilometry. For SEM analysis, the samples after washing with water and acetone were dipped in isopropanol solution for $1 \mathrm{~min}$ to remove excess oil on sample surfaces and dried. The samples were typically mounted in low-shrinkage epoxy under vacuum prior to grinding and polishing to $0.05 \mu \mathrm{m}$ using colloidal silica. The mounted specimen was then coated with a thin layer of palladium for electronic conduction purposes prior to SEM examination. Samples were put in a FEI Nano SEM 650 Scanning Electron Microscope. An AltiSurf 500 laser profilometer was used to map the surface topography and determine the pit distributions. Detailed experimental procedur is described in previous publication ${ }^{5}$.

\section{Wettability}

The presence of free water, or of o/w emulsion, does not necessarily lead to corrosion. Under this condition, wettability of the biodiesel on the metal determines corrosivity. The wettability of PBD and JBD on MS were studied by contact angle method ${ }^{6}$, the significance of which is detailed elsewhere ${ }^{7}$.

\section{Results and Discussion}

The corrosion rate of MS and conductance of various test solutions as determined by static immersion test in PBD and JBD are given in Table 2. The lower corrosion rates in B100 may be attributed to the non-ionic nature of the biodiesels. When $1 \%$ of $3 \% \mathrm{NaCl}$ is added to $\mathrm{B} 100$, the corrosion rate is slightly increased. The addition of $\mathrm{NaCl}$ represents the presence of water. At low concentration of water, biodiesel forms a water-in -oil emulsion. At this stage, biodiesel is the continuous phase hence measured corrosion rate is less in $\mathrm{B} 99$ than $\mathrm{NaCl}$.

Table 2. Mean corrosion rate and conductance of mild steel - static mass loss method

\begin{tabular}{ccccccc}
\hline \multirow{2}{*}{ Medium } & \multicolumn{2}{c}{$\begin{array}{c}\text { Corrosion rate } \\
\text { mpy }\end{array}$} & \multicolumn{3}{c}{ Conductance, $\mathrm{m}^{-1}$} \\
\cline { 2 - 7 } & PBD & JBD & Before & After & Before & After \\
\cline { 2 - 7 } NaCl & 2.34 & 2.45 & 2003 & 3217 & 1793 & 2187 \\
B99 & 1.48 & 1.33 & 0.07 & 0.09 & 0.13 & 0.58 \\
B100 & 0.62 & 0.78 & 0.07 & 0.09 & 0.13 & 0.62 \\
\hline
\end{tabular}

Since wet corrosion is electrochemical in nature, there is a direct correlation between the corrosivity of the medium and conductance. The highly corrosive brine solution has higher conductance. The higher conductance of $\mathrm{NaCl}$ solution after exposure of the mild steel than that before indicates the increased ionic content of the solution due to corrosion of mild steel. The conductivities of B100 and B99 remained the same in both biodiesels establishing the corrosion resistant nature.

Though the negligible corrosion rates were observed in both the cases, corrosion rate in JBD was found to be higher. The higher corrosive nature may be attributed due to the presence of impurities like water, methanol, free fatty acid, catalyst remaining after processing and also from the reversibility of the chemical reaction which produces the esters.

The corrosion rates of MS in PBD, JBD and their blends with CD were presented in Figure 1. The ehaviour of mild steel in JBD, CD and its blends with $\mathrm{CD}$ was found to be almost same and corrosion resistance behaviour has been observed in PBD-CD blending. 


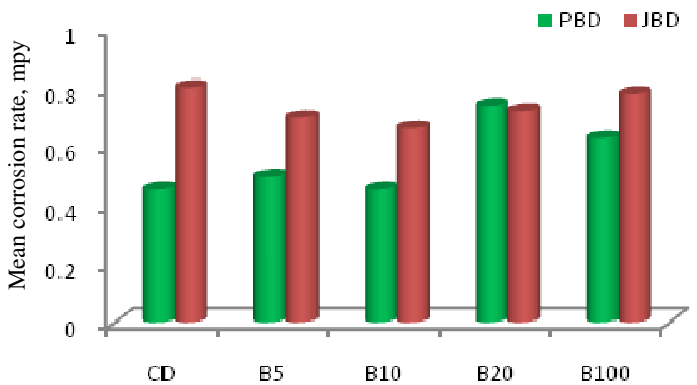

Figure 1. Mean corrosion rates of mild steel in Pongamia, Jatropha biodiesels and their blends with commercial diesel

The corrosion rate of the metal has not been affected upon blending of biodiesel. Hence MS is compatible with the biodiesel and allows the safe use of the metal in biodiesel and its blends.

SEM images of PBD and JBD showed pitting along with some surface deposits (Figure 2). The size and distribution of the pits are not similar in both biodiesels. Pitting corrosion on the metal surface in biodiesels caused by the presence of different types of mono carboxylic acids like formic acid, acetic acid, propionic acid, caproic acid, $e t c^{8}$.
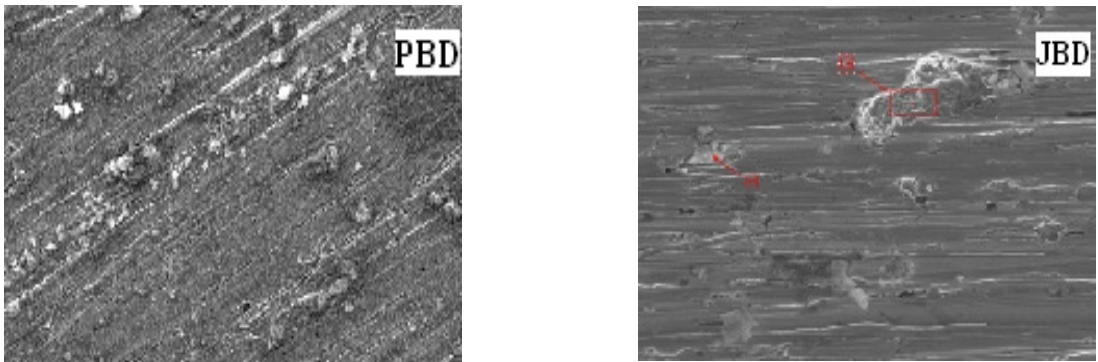

Figure 2. SEM images of mild steel in PBD and JBD

The surface profiles and the pit distribution histograms of the mild steel samples immersed in PBD and JBD are shown in Figures 3 and 4 respectively. The majority of pits present on the mild steel sample immersed in PBD were 30-38 $\mu \mathrm{m}$ and in JBD were 6-10 $\mu \mathrm{m}$. Overall, the total number of pits counted on the surface immersed in JBD is more than PBD indicating the higher corrosivity of JBD.

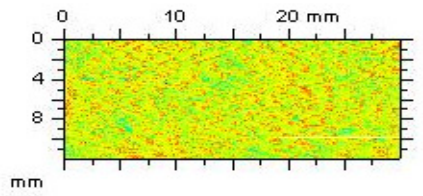

a

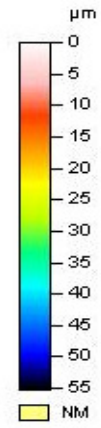

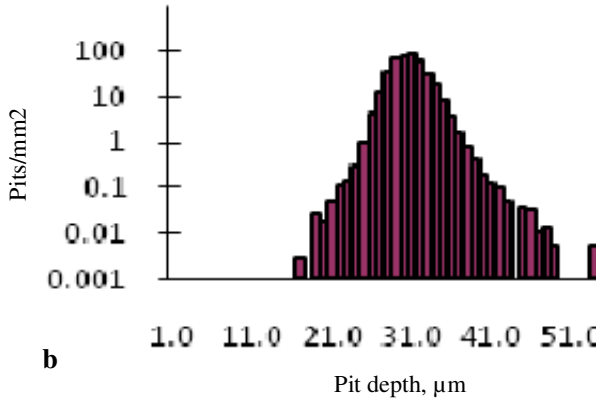

Figure 3. a) Surface profiles; b) Pit distribution histogram of PBD 

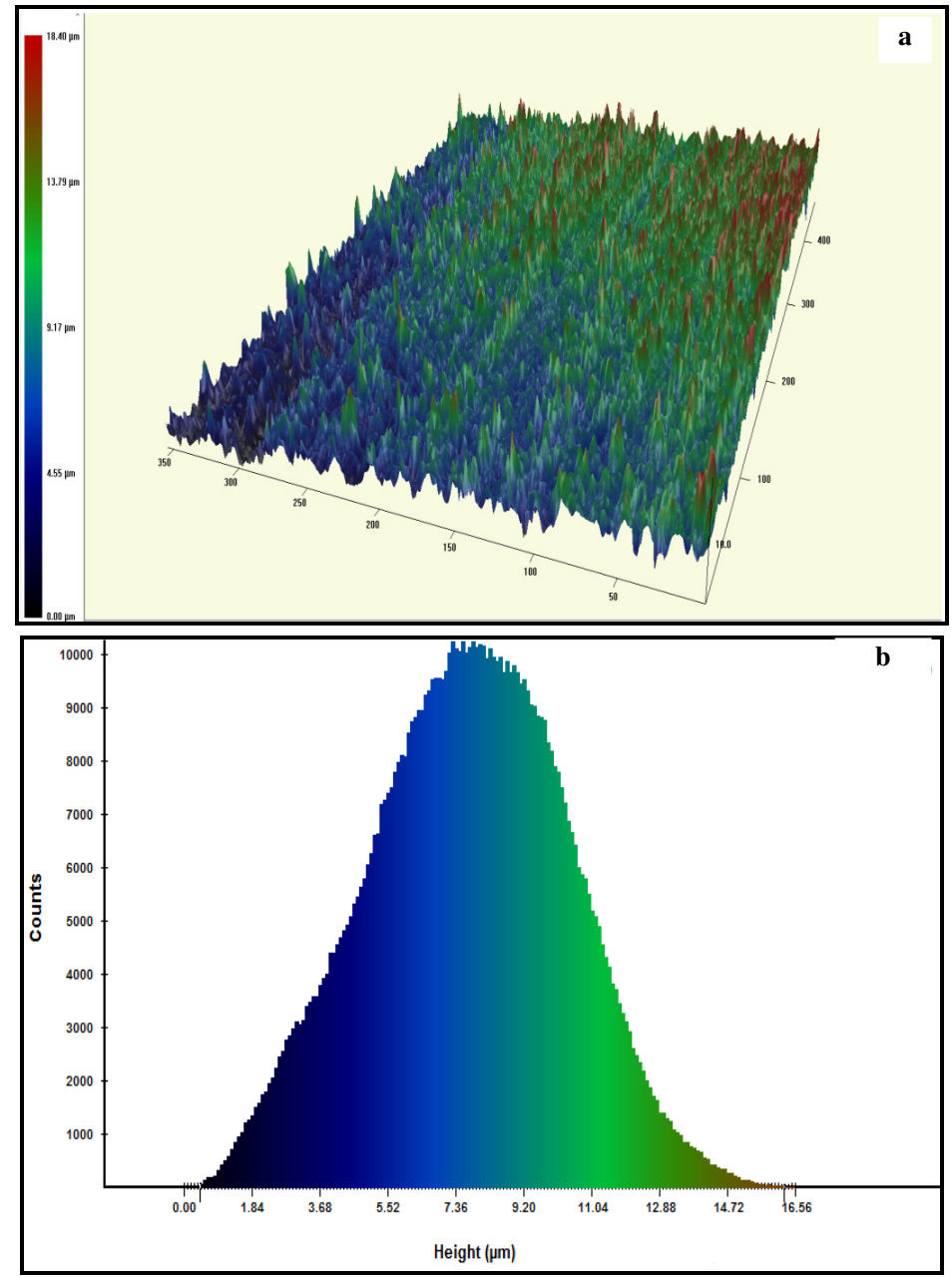

Figure 4. a) Surface profiles; b) Pit distribution histogram of JBD

Water enters into storage tank from various sources. In the presence of free water or oil in water emulsion, the susceptibility of a metal surface to corrosion depends on the wettability. In the present work, the contact angle of the water-biodiesel system on mild steel measured through the water phase is shown in Figure 5. In both cases, the angle was found to be obtuse. When the contact angle is between $90^{\circ}$ and $180^{\circ}$ displacement of water by oil is expected. Hence the system is oil-wet and therefore non corrosive.
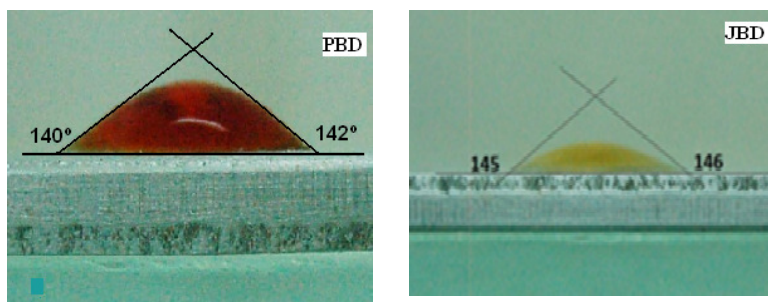

Figure 5. Wettability of PBD and JBD on MS 


\section{Conclusion}

The present investigation shows that mild steel is compatible with Pongamia, Jatropha biodiesels and their blends with commercial diesel, hence allow the safe use of the metal to construct the storage tanks. Though negligible corrosion rates were observed in both the biodiesels, the corrosivity of JBD was found to be higher. The dissimilar behaviour of PBD and JBD on mild steel has confirmed by surface analysis. The non corrosive nature of biodiesels on mild steel is supported by wettability studies.

\section{Acknowledgement}

The authors would like to thank the authorities of Avinashilingam University for Women, Coimbatore for providing necessary facilities to carry out this study. The authors also acknowledge the financial support from Department of Science and Technology (DST).

\section{References}

1. Varanda M G, Pinto G and Martins F, Fuel Proc Technol., 2011, 92, 1087-1094.

2. Rao P V, J Petroleum Technology and Alternative Fuels, 2011, 2, 63-75.

3. Anisha A, Meenakshi H N and Shyamala R, The Ecoscan, Special Issue, 2011, 1, 291-294.

4. Bondioli P, Gasparoli A, Lanzani A, Fedelie, Veroneses and Sala M, J American Oil Chemists' Society, 1995, 699-702.

5. Meenakshi H N, Anisha A, Shyamala R, Saratha R, Jennifer K and Papavinasam S, 2011, NACE Corrosion, 2011: \#11142. http://www.onepetro.org/mslib/servlet/onepetropreview?id=NACE-11142

6. Meenakshi H N, Anisha A, Shyamala R, Saratha R and Papavinasam S, 2010, NACE Corrosion, 2010: \# 10076.

http://www.onepetro.org/mslib/servlet/onepetropreview?id=NACE-10076

7. Papavinasam S, Doiron A, Panneerselvam T and Revie R W, NACE Corrosion, 2007, 63, 704-712.

8. Tsuchiya T, Shiotani H, Goto S, Sugiyama G and Maeda A, Japanese Standards for Diesel Fuel Containing 5\% FAME: Investigation of Acid Generation in FAME Blended Diesel Fuels and Its Impact on Corrosion, 2006; SAE Technical paper: \#01-3303. 